\title{
The Antimicrobial activity and Brine Shrimp Lethality Bioassay of Leaf extracts of Stephania japonica (Akanadi)
}

\author{
Rahman M Minhajur ${ }^{1}$, M Masud Alam², AF M Shahid-Ud-Daula ${ }^{1 *}$, Mohammad Shahriar², \\ Md Mizanur Rahman Moghal $^{1}$ and Rokeya Siddiqui ${ }^{2}$
}

${ }^{I}$ Department of Pharmacy, Noakhali Science and Technology University, Sonapur, Noakhali-3802, Bangladesh, ${ }^{2}$ Department of Microbiology, Noakhali Science and Technology University, Sonapur, Noakhali-3802, Bangladesh, ${ }^{3}$ Department of Microbiology, University of Asia Pacific, Dhanmondi-6A, Dhaka, Bangladesh.

(Received 24 June 2011; Accepted 22 October 2011)

\begin{abstract}
The purpose of the present study is to examine the antibacterial and cytotoxic properties of methanol extract of leaves of Stephania japonica. The crude methanolic extract of $S$. japonica, n-hexane, chloroform and ethyl acetate soluble fractions of methanolic extract were screened for their antimicrobial activity against a wide range of both Gram-positive and Gram-negative bacteria by disc diffusion method. The crude extract showed moderate and n-Hexane, chloroform soluble fraction of crude extract showed mild antibacterial activity against both Gram-positive and Gram-negative bacteria. Ethyl acetate soluble fraction of the extract showed significant antimicrobial activity against Salmonella typhi, Escherichia coli and Bacillus cereus. The zones of inhibition produced by the crude methanolic extract, n-hexane, chloroform and ethyl acetate soluble fractions were found to be $12.80-16.55 \mathrm{~mm}, 12.60 \mathrm{~mm}, 5-14.30 \mathrm{~mm}$ and $10-20.25 \mathrm{~mm}$, respectively, at a concentration of $30 \mathrm{~g} /$ disc. Chloroform, n-hexane and ethyl acetate soluble fractions of methanolic extract of $S$. japonica were screened for antitumor properties using brine shrimp lethality bioassay. A reputed cytotoxic agent vincristine sulphate was used as a positive control. From the results of the brine shrimp lethality bioassay, it can be well predicted that chloroform and ethyl acetate soluble fractions of methanolic extract of $S$. japonica possess cytotoxic principles (with $\mathrm{LC}_{50} 66.488 \mathrm{mg} / \mathrm{ml}$ and $\mathrm{LC}_{50} 45.662 \mathrm{mg} / \mathrm{ml}$, respectively) comparison with positive control vincristine sulphate (with $\mathrm{LC}_{50} 0.839 \mathrm{mg} / \mathrm{ml}$ ). But $\mathrm{n}$-hexane soluble fractions of methanolic extract of $S$. japonica exhibited no lethality effect on shrimp nauplii.
\end{abstract}

Key words: Stephania japonica, Antimicrobial activity, Brine shrimp lethality bioassay.

\section{Introduction}

Infectious diseases worldwide have been known to be a cause of morbidity, disability and mortality. Approximately 15 million people die each year due to infectious diseases - nearly all live in developing countries ${ }^{1}$. Indiscriminate and unconcerned use of antibiotics has led to increased microbial resistance. Consequently, newer agents have been brought in at increased economic costs to the patient but they too have become inefficacious in due course and pose worldwide a great threat to human health. So, noble, emerging and re-emerging infectious diseases have become a focus for the development of new costeffective drug in both developed and developing countries. Nature has been a source of medical treatments for thousands of years and today plant based systems continue to play an important role in the primary health care of $80 \%$ of the world's population ${ }^{2,3}$. Medicinal plant extracts offer considerable potential for the development of new agents effective against infections currently difficult to treat ${ }^{4}$. As natural products have been elaborated within living systems, they are often perceived as showing more 'drug likeness' and biological friendliness than totally synthetic molecules, making them good candidates for further drug development ${ }^{5-7}$. In continuation of this effort, we studied antibacterial potential of Stephania japonica and its cytotoxic properties.

The medicinal plant, $S$. japonica, is an evergreen plant, climber or twiner, slender stems without prickles; leaves are peltate; lamina circular to ovate or triangular, plant size ranges from 4-6 feet. It is widely distributed in temperate Asia such as China, Japan, Taiwan, and in tropical Asia, Indian subcontinent, Australia: New South Wales, and Northern Territory and Queensland.

Different studies were performed on the alkaloids of S. japonica miers, an alkaloidal, isotrilobine of the vines of S. japonica was shown to be as active as verapamil in reversing doxorubicin resistance in human breast cancer cells ${ }^{8}$. Two new and six known hasubanan alkaloids and one morphinane alkaloid were isolated from the leaves of the north queensland rainforest vine S. japonica. The hasubanan alkaloids showed affinity for the human deltaopioid receptor with $\mathrm{ic}_{(50)}$ values ranging from 0.7 to 46 micron. 
The compounds were also tested for their affinity to micro and kappa-opioid receptors and shown to be inactive against kappaopioid receptors, but were of similar potency against the microopioid receptor ${ }^{9}$.

\section{Materials and Methods}

\section{Bacterial Strains}

Six Gram positive and Gram negative bacterial strains were obtained from the stock culture of the Department of Pharmacy, University of Asia Pacific, Bangladesh (Table 1). These strains were grown in nutrient broth (Difco Laboratories, USA) at $37^{\circ} \mathrm{C}$ and maintained on nutrient agar slants at $4{ }^{\circ} \mathrm{C}$.

\section{Plant materials}

The plant $S$. japonica was collected from the Noakhali district, Bangladesh. The plant was identified by the Bangladesh National Herbarium, Dhaka, and a voucher specimen (Accession No: 35981) was deposited at the Department of Pharmacy, Noakhali Science and Technology University. The leaves were collected from the fresh tree. And then dried in an oven tray for 2 days at $40^{\circ} \mathrm{C}$ to $45^{\circ} \mathrm{C}$. After drying, the plant part was ground into fine powder, which was almost red in colour.

\section{Preparation of extracts}

The plant extract was made by cold extraction method. Four hundred gram of powder was soaked in $1300 \mathrm{ml}$ of $90 \%$ methanol. The container with its contents was sealed and kept for a period of 7 days with occasional shaking and stirring. The whole mixture was then filtered a coarse piece of clean, white cotton fabric. Then it was filtered through Whatman filter paper No-3. and the filtrate thus obtained was concentrated by evaporation and dried to a solid in an oven (Memmert: DIN12880-KI). Finally, reddish colour primary methanolic extract was found. Next, $5 \mathrm{~g}$ of primary methanolic extract was dissolved in $100 \mathrm{ml}$ of $90 \%$ methanol. This is the mother solution, which was partitioned off successively by solvent-solvent extraction methods with three solvents of different polarity such as n-hexane, ethyl acetate, and chloroform.

\section{Antibacterial Screening}

The antimicrobial activity of the methanolic, n-hexane, ethyl acetate and chloroform extracts of $S$. japonica leaves sample were evaluated using agar disc-diffusion according to the Kirby Bauer method against the six Gram positive and Gram negative test organisms. The final concentrations of test samples were 3 $\mu \mathrm{g} / \mu \mathrm{l}$ by dissolving the test samples with specific volume of solvents (Table 2).

Sterile Whatman filter paper discs ( $5 \mathrm{~mm}$ in diameter) were taken in a petridish. One drop of sample solution of the $3 \mu \mathrm{g} / \mu \mathrm{l}$ concentration was applied on the discs with the help of a micropipette in an aseptic condition. These discs were left for few minutes in aseptic condition for complete removal of solvent. Kanamycin $(30 \mu \mathrm{g} / \mathrm{disc})$ standard discs were used as a positive control. Blank discs and one drop of disc containing each solvent were used as a negative control.
Tested bacterial samples from the stock culture were transferred to the nutrient agar slants medium for making fresh culture of microorganisms. The inoculated slants were then incubated at $37^{\circ} \mathrm{C}$ for 18-24 hours and then from the slants fresh culture was transferred to the test tube containing liquid nutrients to make a uniform suspension of organisms. The bacterial suspensions were immediately poured onto nutrient agar plate to give a uniform layer of bacteria. Excess bacterial suspension was taken out with a sterile Pasteur pipette. Impregnated test sample, standard antibiotic and negative control discs were placed gently on the freshly seeded solidified agar plates using sterile forceps to assure complete contact with medium surface. The spatial arrangements of the discs were such that the discs were not closer than $15 \mathrm{~mm}$ to the edge of the plate and far enough apart to prevent overlapping the zones of inhibition. Plates were kept at refrigeration temperature for $3-4 \mathrm{~h}$ for better absorption, during this time microorganisms will not grow but absorption of extracts would take place. Finally, the plates were incubated upside down at $37^{\circ} \mathrm{C}$ for $12-18$ hours.

Table 1. Lists of bacteria were used for antimicrobial screening

\begin{tabular}{ll}
\hline Gram negative & Gram positive \\
\hline Escherichia coli & Staphylococcus aureus \\
Vibrio cholerae & Bacillus subtilis \\
Salmonella typhi & Bacillus cereus \\
\hline
\end{tabular}

Table 2. Preparation of test solutions

\begin{tabular}{lccc}
\hline Sample & $\begin{array}{c}\text { Amount } \\
(\mathrm{mg})\end{array}$ & $\begin{array}{c}\text { Solvent type } \\
\text { and their } \\
\text { volume }(\mathrm{ml})\end{array}$ & $\begin{array}{c}\text { Final } \\
\text { concentrations } \\
(\mu \mathrm{g} / \mu \mathrm{l})\end{array}$ \\
\hline Crude (Methanol) extract & 30 & Methanol, 10 & 3 \\
n-Hexane fraction & 30 & n-Hexane, 10 & 3 \\
Chloroform fraction & 30 & Chloroform, 10 & 3 \\
Ethyl Acetate fraction & 30 & Ethyl acetate, 10 & 3 \\
\hline
\end{tabular}

\section{Brine Shrimp Lethality Bioassay}

The brine shrimp lethality bioassay of the methanolic, ethyl acetate and chloroform extracts of $S$. japonica leaf samples were evaluated according Meyer protocol ${ }^{10}$ against the Artemia salina as a test organism to monitor cytotoxicty of a compound. In this lethality bioassay, it is estimated that $\mathrm{LC}_{50}$ values with $95 \%$ confidence intervals for statistically significant comparisons of potencies.

\section{Hatching of brine shrimps}

Thirty eight gram of sea salt (pure $\mathrm{NaCl}$ ) was dissolved in one litter of distilled water and filtered to get clear solution. Seawater was taken in the small tank and A. salina leach (brine shrimp eggs) was added to one side of the tank and then this side was covered. These were allowed two days to hatch the shrimp and to be matured as nauplii. Constant oxygen supply was provided throughout the hatching time. The hatched shrimps were attracted to the lamp through the perforated dam and with the help of a Pasteur pipette 10 living shrimps were added to each of the vials containing $5 \mathrm{ml}$ of seawater. 
Preparation of the different concentrations of n-haxane, ethyl acetate and chloroform soluble fractions of methanolic extracts of $S$. japonica

Different concentrations of extracts were prepared by dissolving them in DMSO to attain a concentrations of $0.78125,1.5625,3.125$, $6.25,12.5,25,50,100,200$ and $400 \mu \mathrm{g} / \mathrm{ml}$. Then $100 \mu \mathrm{l}$ of each concentration of different extracts were added to the $5 \mathrm{ml}$ of simulated seawater-shrimp nauplii.

Preparation of the different concentrations of positive and negative control groups for lethality bioassay

Standard vincristine sulphate was used as positive control. Measured amount of the vincristine sulphate was dissolved in DMSO to attain the initial concentration of $40 \mathrm{mg} / \mathrm{ml}$ from which serial dilutions were made using DMSO to get $20,10,5,2.5,1.25$, $0.625,0.3125,0.15625$ and $0.078125 \mathrm{mg} / \mathrm{ml}$. Then these solutions were added to the tubes containing ten living brine shrimp nauplii in $5 \mathrm{ml}$ simulated sea water to get the positive control groups.

$100 \mathrm{ml}$ of DMSO was added to each of three glass tube containing $5 \mathrm{ml}$ of simulated sea water-shrimp nauplii to use as negative control groups. If the brine shrimps in these vials show a rapid mortality rate, then the test is considered as invalid as the nauplii died due to some reason other than the cytotoxicity of the compounds. Then matured shrimps were applied to each of all experimental vials and control vial. After $24 \mathrm{~h}$, the vials were inspected using a magnifying glass and the number of survived nauplii in each vial was counted. From this data, the percent (\%) of mortality of the brine shrimp nauplii was calculated for each concentration using the following formula:

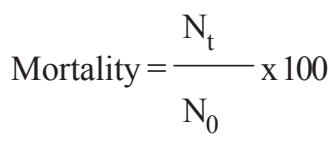

Where, $\mathrm{Nt}=$ Number of killed nauplii after $24 \mathrm{hrs}$ of incubation, No $=$ Number of total nauplii transferred i.e 10.

The $\mathrm{LC}_{50}$ (Median lethal concentration) was then determined using Regression analysis.

\section{Results and Discussion}

\section{Antimicrobial Test}

The result of the antimicrobial activity was measured in terms of diameter of zones of inhibition in $\mathrm{mm}$ (millimeter) with standard deviation are shown in Table 3. The crude sample (methanolic extract), $n$-Hexane, chloroform and ethyl acetate soluble fractions for antimicrobial activity was used in single concentration $30 \mu \mathrm{g} /$ disc.

The zones of inhibition produced by the crude methanolic extract, n-hexane, chloroform and ethyl acetate soluble fractions were found to be $12.8-16.55 \mathrm{~mm}, 12.6 \mathrm{~mm}, 5-14.3 \mathrm{~mm}$ and $10-20.25 \mathrm{~mm}$ respectively at a concentration of $30 \mathrm{mg} / \mathrm{disc}$. The crude extract showed significant activity against $E$. coli $(16.22 \mathrm{~mm})$, S. typhi $(16.55 \mathrm{~mm})$. The crude extract showed moderate activity against B. cereus (12.8 mm), B. subtilis (13.5mm), S. aureus (13.6), V. cholera $(14.5 \mathrm{~mm})$. Crude methanolic extract of S. japonica leaf was investigated for possible antioxidant, analgesic, antimicrobial and cytotoxic activity ${ }^{11}$.

The n-hexane soluble fraction exhibited moderate activity against S. typhi $(12.6 \mathrm{~mm})$. The n-hexane soluble fraction showed no activity against $B$. cereus, B. subtilis, S. aureus, E. coli, S. typhi and V. cholera. The chloroform soluble fraction exhibited mild activity against $B$. subtilis $(5 \mathrm{~mm}), S$. aureus $(8.7 \mathrm{~mm}), S$. typhi $(8 \mathrm{~mm}), V$. cholera $(5.1 \mathrm{~mm})$. The chloroform soluble fraction exhibited moderate activity against $E$. coli $(14.3 \mathrm{~mm})$, but showed no activity against $B$. cereus.

The ethyl acetate soluble fraction exhibited significant activity against $B$. cereus $(20.25 \mathrm{~mm})$, E. coli $(20 \mathrm{~mm})$ and $S$. typhi $(16.5$ $\mathrm{mm})$. The ethyl acetate soluble fraction exhibited moderate activity against $B$. subtilis $(10 \mathrm{~mm})$ and $V$. cholera $(11 \mathrm{~mm})$. The ethyl acetate soluble fraction exhibited no activity against $S$. aureus.

\section{Brine shrimp lethality bioassay}

In the present bioactivity study, the chloroform and ethyl acetate fractions of methanolic extract showed positive results indicating that the test samples are biologically active (Table 4). Each of

Table 3. Antimicrobial activity of the crude methanolic extract, n-hexane, chloroform and ethyl acetate soluble fractions of $S$. japonica.

\begin{tabular}{|c|c|c|c|c|c|}
\hline Test Organisms & \multicolumn{5}{|c|}{ Diameter of zones of inhibition (in mm) } \\
\hline \multicolumn{6}{|l|}{ Gram negative } \\
\hline Escherichia coli & $16.22 \pm 0.22$ & - & $14.30 \pm 0.60$ & $20 \pm 0.50$ & $17.70 \pm 0.30$ \\
\hline Vibrio cholerae & $14.50 \pm 0.25$ & - & $5.10 \pm 0.10$ & $11 \pm 0.30$ & $25.20 \pm 0.41$ \\
\hline \multicolumn{6}{|l|}{ Gram positive } \\
\hline Bacillus cereus & $12.80 \pm 0.33$ & - & - & $20.25 \pm 0.21$ & $22.80 \pm 0.67$ \\
\hline Bacillus subtilis & $13.50 \pm 0.34$ & - & $5 \pm 0.41$ & $10 \pm 0.31$ & $22 \pm 0.18$ \\
\hline Staphylococcus aureus & $13.60 \pm 0.51$ & - & $8.70 \pm 0.35$ & - & $21 \pm 0.60$ \\
\hline
\end{tabular}

(-): No inhibition 
Minhajur et al.

Table 4. Effect of n-hexane, chloroform and ethyl acetate soluble fraction of S. japonica on shrimp nauplii

\begin{tabular}{|c|c|c|c|c|c|c|c|}
\hline \multirow{2}{*}{$\begin{array}{l}\text { Test samples } \\
\text { Conc }(\mathrm{C})(\mathrm{g} / \mathrm{ml})\end{array}$} & \multirow[b]{2}{*}{$\log C$} & \multicolumn{3}{|c|}{$\%$ Mortality } & \multicolumn{3}{|c|}{ Vincristine Sulfate } \\
\hline & & n-Hexane & Chloroform & Ethyl acetate & Conc $(\mathrm{C})(\mathrm{mg} / \mathrm{ml})$ & $\log C$ & $\%$ Mortality \\
\hline 400 & 2.602 & 0 & 100 & 100 & 40 & 1.602 & 100 \\
\hline 100 & 2 & 0 & 60 & 70 & 10 & 1.000 & 90 \\
\hline 50 & 1.699 & 0 & 20 & 50 & 5 & 0.698 & 80 \\
\hline 25 & 1.398 & 0 & 10 & 20 & 2.5 & 0.397 & 70 \\
\hline 3.125 & 0.495 & 0 & 0 & 0 & 0.3125 & -0.505 & 30 \\
\hline 1.5625 & 0.194 & 0 & 0 & 0 & 0.15625 & -0.806 & 20 \\
\hline 0.78125 & -0.107 & 0 & 0 & 0 & 0.078125 & -1.107 & 10 \\
\hline
\end{tabular}

these test samples showed different mortality rates at different concentrations (Fig.1). Plotting of log of concentration versus percent mortality for these test samples showed an approximate linear correlation. From the graphs, the median lethal concentration $\left(\mathrm{LC}_{50}\right.$, the concentration at which $50 \%$ mortality of
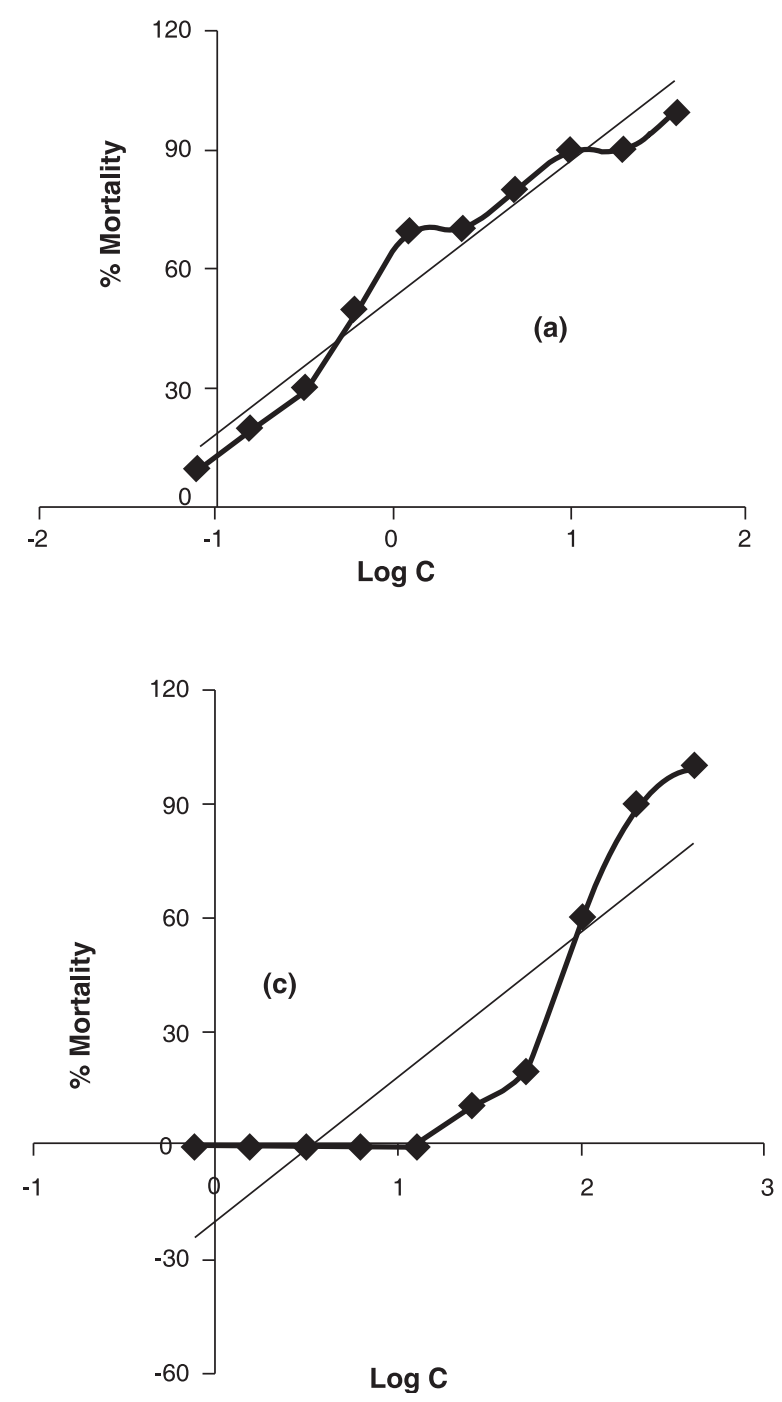

brine shrimp nauplii occurred) was determined for the samples. In this study n-hexane fraction did not show positive activity. The positive control groups showed non linear mortality rates at lower concentrations and linear rates at higher concentrations. There was no mortality in the negative control groups indicating
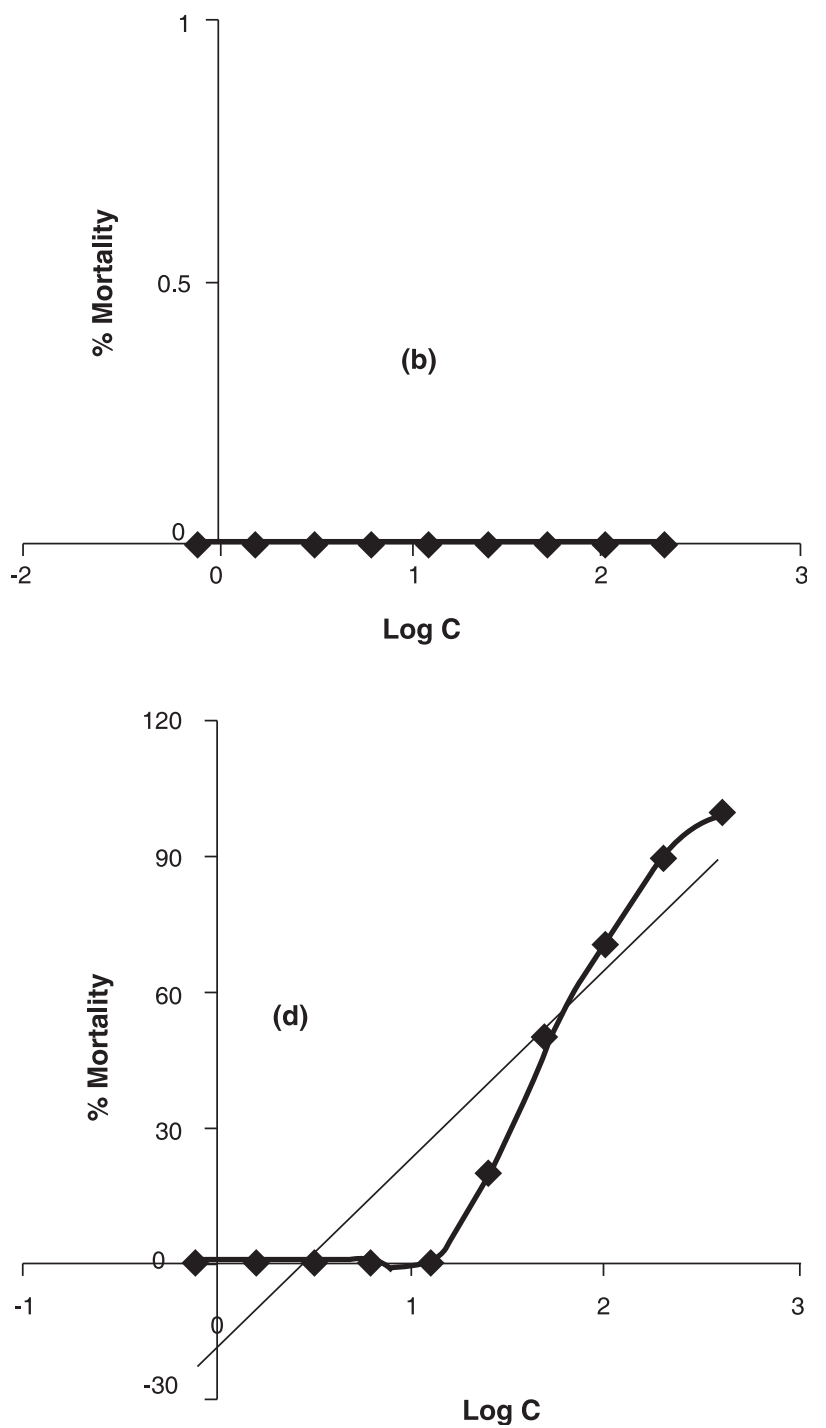

Fig 1. Mortality rates of the test samples at different concentrations on shrimp nauplii. a, Vincristine sulphate; $b, n$-haxane soluble fraction; c, Chloroform soluble fraction; $d$, Ethyle acetate soluble fraction. 
The Antimicrobial activity and Brine Shrimp Lethality Bioassay

Table 5. Results of the test samples of S. japonica

\begin{tabular}{lccc}
\hline Sample & $\mathrm{LC}_{50}(\mathrm{mg} / \mathrm{ml})$ & Regression equation & $\mathrm{R}^{2}$ \\
\hline Vincristine sulphate (positive control) & 0.839 & $\mathrm{y}=34.027 \mathrm{x}+52.588$ & 0.9168 \\
n-Hexane soluble fractions of methanolic extract & 0 & $\mathrm{y}=0$ & $\# \mathrm{~N} / \mathrm{A}$ \\
Chloroform soluble fractions of methanolic extract & 66.488 & $\mathrm{y}=38.25 \mathrm{x}-19.72$ & 0.761 \\
Ethyl acetate soluble fraction of methanolic extract & 45.662 & $\mathrm{y}=41.27 \mathrm{x}-18.49$ & 0.848 \\
\hline
\end{tabular}

the test as a valid one and the results obtained are only due to the activity of the test agents.

The $\mathrm{LC}_{50}$ values of chloroform and ethyl acetate soluble fraction found to be $66.488 \mathrm{mg} / \mathrm{ml}$, and $45.662 \mathrm{mg} / \mathrm{ml}$ respectively (Table $5)$. But n-hexane soluble fraction showed no cytotoxic activity. The positive control vincristine sulphate showed $\mathrm{LC}_{50}$ at a concentration of $0.839 \mathrm{mg} / \mathrm{ml}$. Comparison with positive control vincristine signifies that cytotoxicity exhibited by the chloroform and ethyl acetate soluble fraction might have mild antitumor and pesticidal activity. The extract also showed significant cytotoxicity on brine shrimp nauplii. This may be due to the fact that $S$. japonica contains isotrilobine and trilobine, bisbenzylisoquinoline alkaloids, which was previously reported to possess multidrug-resistance reversing activity in human breast cancer cell line ${ }^{11,12}$. However this cannot be confirmed without further higher and specific tests.

The pharmacological investigation for antimicrobial activity of crude extract (methanolic extract) of S. japonica and n-Hexane, chloroform and ethyl acetate soluble fractions of methanolic extract showed a moderate microbial growth inhibitory effect against both Gram positive and Gram negative bacteria tested. As the pharmacological activity of any antimicrobial substance depends on its applied dose and in this experiment we applied dose $30 \mathrm{microgram} / \mathrm{disc}$. From the experiment we can come to the decision that the plant $S$. japonica contains antimicrobial property. The results of the present study are in agreement with those obtained by Rahman and Alam ${ }^{11}$ and indicated that the leaf extract of S. japonica exhibited antimicrobial properties on both Gram positive and Gram negative microorganisms.

In this study, it is also investigated for antitumor properties of nhexane, chloroform and ethyl acetate soluble fractions of methanolic extract of this plant by using brine shrimp lethality bioassay. From the results of the brine shrimp lethality bioassay it can be well predicted that both the chloroform and ethyl acetate soluble fraction possess cytotoxic principles. Comparison with positive control vincristine signifies that cytotoxicity exhibited by the chloroform and ethyl acetate soluble fraction might have mild antitumor and pesticidal activity.

\section{References}

1. WHO. The global burden of disease: 2004 update. World Health Organization, 2008. Available at www.who.int/healthinfo/ global_burden_diseasel 2004 _report_updatelen/index.html. Accessed Feb 26, 2011

2. Duraipandiyan V, Ayyanar M, Ignacimuhu S. 2006. Antimicrobial activity of some ethnomedicinal plants used by Paliyar tribe from Tamil Nadu, India, BMC Comp. Alter Med, 6: 35-41.

3. Farnsworth NR, Akerele O, Bingel AS, et al. 1985. Medicinal plants in therapy Bull WHO, 63(6): 965-981.

4. Machado TB, Leal ICR, Amaral ACF, et al. 2005. Brazilian phytopharmaceuticals evaluation against hospital bacteria. Phytother Res. 19: 519-525.

5. Koehn FE, Carter GT. 2005. The evolving role of natural products in drug discovery. Nat Rev Drug Discov. 4: 206-220.

6. Balunas MJ, Kinghorn AD. 2005. Drug discovery from medicinal plants. Life Sci. 78: 431-441.

7. Drahl C, Cravatt BF, Sorensen EJ. 2005. Protein-reactive natural products. Angew Chem Int Ed Engl, 44: 5788-5809

8. Hall AM, Chang CJ. 1997 Nov. Multidrug-resistance modulators from Stephania japonica. J Nat Products, 60(11): 1193-5.

9. Carroll AR, Arumugan T, Redburn J, NGO A, Guymer GP, Forster PI, Quinn RJ. 2010. Hasubanan alkaloids with delta-opioid binding affinity from the aerial parts of Stephania japonica. J. Nat. Products, 73(5): 988-91.

10. Meyer BN, Ferringni N R, Puam JE, Lacobsen LB, Nichols DE, and Mclaughlin J L. 1982. 'Brine shrimp: a convenient general bioassay for active constituents.' Planta Medica. 45: 31-32.

11. Rahman M H, Alam M B, Chowdhury N S, Jha M K, Hasan M, Khan M M, Rahman M S and Haque M. E. 2011. Antioxidant, analgesic and toxic potentiality of Stephania japonica (Thunb.) Miers. Leaf. Int J Pharmacol. 7(2): 257-262.

12. Andrea M, Chang C J. 1997. Multidrug- Resistance Modulators from Stephania japonica. J Nat Prod. 60(11): 1193-1195. 